BMJ Open

Diabetes

Research

\& Care

\title{
Model to improve cardiometabolic risk factors in Palestine refugees with diabetes mellitus attending UNRWA health centers
}

\author{
Nada Abu Kishk, ${ }^{\oplus 1}$ Yousef Shahin, ${ }^{1}$ Joanna Mitri, ${ }^{2}$ Yassir Turki, ${ }^{1}$ Wafaa Zeidan, ${ }^{1}$ \\ Akihiro Seita $^{1}$
}

To cite: Abu Kishk N, Shahin Y, Mitri J, et al. Model to improve cardiometabolic risk factors in Palestine refugees with diabetes mellitus attending UNRWA health centers. BMJ Open Diab Res Care 2019;7:e000624. doi:10.1136/ bmjdrc-2018-000624

- Additional material is published online only. To view please visit the journal online (http://dx.doi.org/10.1136/ bmjdrc-2018-000624).

Received 17 0ctober 2018 Revised 21 May 2019 Accepted 18 June 2019
Check for updates

\section{(C) Author(s) (or their} employer(s)) 2019. Re-use permitted under CC BY-NC. No commercial re-use. See rights and permissions. Published by BMJ.

${ }^{1}$ Health, UNRWA Jordan, Amman, Jordan

2Joslin Center, Harvard Medical School, Boston, Massachusetts, USA

\section{Correspondence to} Nada Abu Kishk; nada_abukishk@hms.harvard. edu

\section{ABSTRACT}

Introduction

The United Nations Relief and Works Agency for Palestine

Refugees in the Near East (UNRWA) is the main primary healthcare provider and provides assistance and protection to around 5 million Palestine refugees in Jordan, Lebanon, Syria, West Bank and Gaza. Diabetes mellitus (DM) is a common problem among Palestine refugees, with a prevalence of $11.0 \%$. In 2014, UNRWA embarked on a diabetes campaign to assist both patients with DM and staff in improving diabetes care management, by building the capacity of UNRWA's health staff and improving the knowledge and lifestyle behaviors among Palestine refugees with DM.

Method

Using a quasiexperimental study, we randomly selected 50 patients with diabetes from the 32 largest UNRWA health centers (HC); a total of 1600 participants were enrolled. Each $\mathrm{HC}$ conducted weekly group sessions for 6 months, including education, healthy cooking, and physical exercise. Body measurements, 2-hour postprandial glucose test, blood pressure and session attendance were collected on a weekly basis. Demographical data, pre/ postquestionnaires and cholesterol levels were collected before and after the campaign. Paired t-test in SPSS V.21 was used.

Results

Out of 1600 patients, 1598 (1186 (74.0\%) females and $412(26.0 \%)$ males) completed the campaign; $576(36.0 \%)$ patients had diabetes type 2 (DMII), $960(60.0 \%)$ had DMII and hypertension and 62 (4.0\%) had diabetes type 1 (DMI). After the campaign, the average weight loss was $2.6 \mathrm{~kg}$ (95\% Cl 2.4 to 2.7). In addition, $22 \%$ lost $\geq 5 \%, 25 \%$ lost $3 \%-5 \%$, and $30 \%$ lost $1 \%-3 \%$ of their weight. Significant improvements were seen in blood glucose, cholesterol and waist circumference (WC) ( $p \leq 0.001$ for all). The session attendance rate was $70.6 \%$ in total.

Conclusions

This campaign focused on raising healthy lifestyle awareness and practices among Palestine refugees with DM. It was associated with reduction cardiometabolic risk factors. Similar campaigns need to be sustained and expanded. Local community and non-governmental organization partnerships observed during the campaign should be strengthened and sustained.

\section{Significance of this study}

What is already known about this subject?

- Lifestyle intervention studies are successful in leading to weight loss in patients with diabetes.

- According to the United Nations Relief and Works Agency for Palestine Refugees in the Near East's clinical audit results the prevalence of diabetes is $11 \%$. It was revealed that over $90 \%$ of patients with diabetes mellitus (DM) are overweight or obese, with the majority (64\%) being obese.

What are the new findings?

- This campaign had positive impact on body measurements and blood glucose in Palestine refugees with DM.

How might these results change the focus of research or clinical practice?

- More studies should be done to study the effect of using variety of educational sessions, specially cooking and exercise session, in the refugee camp settings.

\section{INTRODUCTION}

Mandated by the United Nations (UN) General Assembly, the United Nations Relief and Works Agency for Palestine Refugees in the Near East (UNRWA) started its operations in 1950. It provides humanitarian assistance and protection to the registered Palestine refugees in the five fields, including West Bank, Jordan, Lebanon, the Gaza Strip and Syria. Funded entirely by voluntary contributions by different donors, UNRWA's humanitarian services and human development encompass education, primary healthcare, relief and social services, camp improvement and emergency response in situations of armed conflict. It is the main primary healthcare provider for Palestine refugees. ${ }^{12}$ Palestine refugees represent the largest refugee population in the world. ${ }^{2}$ 
UNRWA has been providing healthcare for patients with diabetes mellitus and hypertension (DM\&HTN) in its health centers (HC) since 1992. UNRWA's diabetes care includes screening of high-risk groups, diagnosis and treatment. In 2014, UNRWA had more than 231000 registered Palestine refugee patients with non-communicable disease (NCD). The increased burden of NCDs presents a tremendous challenge for the agency accounting for $41 \%$ of its total budget spent on medications. With an ageing population, the primary challenge is no longer communicable diseases; rather, it is actually in dealing with comorbidities associated with NCDs.DM, cardiovascular diseases and other NCDs are now responsible for $70.0 \%$ of deaths in UNRWA's population. ${ }^{2}$

Heart diseases, cerebrovascular diseases, and cancers are the major causes of morbidity and mortality for the population in occupied Palestinian territory and some of the neighborhood countires. ${ }^{3}$ According to UNRWA's 2014 records, the prevalence of diabetes among the general population where Palestine refugees live is known to be $10.1 \%$ in Jordan; $7.8 \%$ in Lebanon; $8.6 \%$ in Palestine; and $10.8 \%$ in Syria. ${ }^{4}$ The urbanization and continuing nutritional change from a healthy Mediterranean diet to an increasingly Western-style diet are associated with a decrease in physical activity, obesity, and a loss of the traditional diet benefits. ${ }^{4}$ As seen throughout all of UNRWA's areas of operation, specifically for Palestine refugees, they experience a high level of stress due to many environmental stressors: the ongoing political tension and conflict, lack of security, high rate of unemployment, and poor infrastructure in refugee camps. Consequently, there has also been a rise in NCDs, especially diabetes, HTN, and mental disorders. ${ }^{3}$

Obesity is recognized as one of the most important risk factors for DMII, as it induces insulin resistance and pancreatic beta-cell dysfunction. ${ }^{5}$ Studies have demonstrated that lifestyle interventions are successful in leading to weight loss in patients with diabetes. ${ }^{6}$ There are different challenges that UNRWA faces when dealing with diabetes care, ${ }^{12}$ therefore, to acquire information on the diabetes care in the UNRWA HC, the agency has performed a clinical audit in 2012. It was revealed from this clinical audit that over $90 \%$ of patients with DM are overweight or obese, with the majority (64\%) being obese. UNRWA's clinical audit had recommended many action steps to be taken, such as: developing a comprehensive package of lifestyle support activities that can be implemented in HCs at no additional cost. It also recommended that UNRWA should change the involvement of nurses and paramedical staff in diabetes care delivery to be more proactive, in order to improve health promotion, education and adherence. ${ }^{7}$

Responding to the above results, in 2013 UNRWA's health department embarked on a campaign titled 'Life is Sweeter with Less Sugar' which aimed to assist both patients and healthcare providers in changing their attitude and behavior to prevent and control diabetes among Palestine refugees attending UNRWA HCs. Additionally, within Palestine refugee camps, it included efforts to raise the local community's awareness of the risk factors that can lead to one's development of diabetes and stressed the importance of healthy lifestyle practices. Funded by the World Diabetes Foundation, this campaign consisted of two prongs: first, outreach and screening activities for detecting new cases of diabetes within the local community; and second, conducting educational group sessions for the registered patients with DM at UNRWA HCs in Jordan, West Bank, Gaza and Lebanon. Also, on a weekly basis for 6 months, $30 \mathrm{HCs}$ conducted educational, healthy cooking, and exercise group sessions for its local communities.

Body measurements, blood tests, and patients' attendance records were collected monthly. There were 1174 (951 females, 223 males) who completed the diabetes campaign (out of 1300 who were recruited). After the campaign, $185(16 \%)$ lost $\geq 5 \%, 226(22 \%)$ has lost between $3 \%$ and $5 \%$ and $377(33 \%)$ has lost between $1 \%$ and $3 \%$ of their weight. Waist circumference (WC) mean decreased from $108.5 \pm 13.1 \mathrm{~cm}$ to $106 \pm 13.2 \mathrm{~cm}$ with $(-2.6 \pm 4.9 \mathrm{~cm})$ reduction in the total mean. Also, significant improvements were seen in blood glucose and cholesterol $(\mathrm{p}<0.001){ }^{8}$

Social networks play a strong role in people's health behavior, especially in a refugee camp setting. Since diabetes management requires behavioral changes and adherence to healthy lifestyle practices, social support is considered to be one of the influential and important factors for performing self-care and for adherence to the treatment and disease control. ${ }^{9}$ In order to validate this model of care delivery in refugee camps, UNRWA's health department has expanded this campaign and replicated it in 32 UNRWA HCs, with the objectives of improving the cardiometabolic risk factors, knowledge and lifestyle behaviors of diabetes care management among Palestine refugees with DM, and enhancing the capacity and technical skills of UNRWA's health staff for better delivery of diabetes care management to the Palestine refugees who attend UNRWA HCs.

\section{METHODOLOGY}

In a quasiexperimental design without control group, ${ }^{10}$ we aimed to to expand on the model used in 2013 for diabetes care among refugees. ${ }^{8}$ The intervention, labeled as DM campaign, took place in UNRWA HCs across four fields (Jordan, the West Bank, Lebanon, and Gaza). The intervention consisted of three components: (1) physical activity session, (2) healthy cooking session, and (3) disease management session.

Due to the complexity of the refugee setting, we used a quasiexperimental design as we cannot have a control group in refugee camp settings. We think it was not feasible or ethical for a UN agency such as UNRWA to conduct a randomized controlled study on their beneficiaries. 
Patient enrollment and HCs selected

Inclusion and exclusion criteria

- Patients attending the selected HCs with confirmed (based on the diagnostic criteria in HCs) fasting blood glucose (FBG) reading above $126 \mathrm{mg} / \mathrm{dL}$, or two positive readings of 2-hour postprandial blood glucose (2hrPPG) above $180 \mathrm{mg} / \mathrm{dL}$, or oral glucose tolerance test if the FBG is between 110 and $125 \mathrm{mg}$ / dL.

- DM, both DMI (with or without HTN) and DMII (with or without HTN), and had received care at UNRWA NCD clinics for at least 1 year.

Patients were willing and committed to participatinge in all planned activities and gave verbal informed consent.

Our exclusion criteria were non-Palestine refugees with DM or Palestine refugees who are not registered in UNRWA HCs.

\section{Sampling}

For the DM campaign sampling, we followed the same procedure used in UNRWA's clinical audit, ${ }^{7}$ as it included 1600 patients with diabetes which were selected from the 32 largest UNRWA HCs in four of UNRWA's fields: Gaza, Jordan, Lebanon and West Bank. For this second diabetes campaign, we followed the same clinical audit sampling methodology as follows: eight of the largest HCs in each field were chosen to be included in the campaign and each selected HC was instructed to randomly select 50 patients with DM or DM\&HTN from their NCD clinics. Therefore, the total number of participants enrolled was 1600 ( 50 patients from the eight largest HCs in four fields of UNRWA's operation) for 6 months.

After verbal consent, patients were selected to be part of the campaign activities. Before starting the activities, all selected HCs were provided with posters and brochures to promote the launch of the campaign and its activities.

\section{Activities conducted}

The campaign took place from May 2014 to February 2015, we scaled up its activities compared with the first campaign in 2013. ${ }^{8}$ An intensive preparation phase had taken place, with more focus on handling the obstacles that might face UNRWA HCs, before launching the campaign. An active communication channel between health departments in the headquarter, field offices, camp offices, local non-governmental organizations (NGO), and high members of the camp community was in place. A 3-day Training of Trainers (ToT) had taken place for the selected number of UNRWA's health staff, who are directly involved in the campaign across the four fields. Staff were trained on standardized educational material for diabetes care management that was delivered to the patients. They were also trained on standardized methods for the campaign's weekly activities, logistics, patients' assessments, reporting, and most importantly counseling skills and presentation skills for conducting the educational sessions. It was then followed by an intensive NCD technical training for UNRWA's physician done by recruited diabetes specialists across the five fields. The training included advance diabetes care management treatment that was in adherence with UNRWA's NCD technical instructions. These ToTs carried out a 3-day training on the same materials for their colleagues in their HCs.

HCs conducted a variety of group sessions interactively and excitingly as possible. As such, based on the schedule of every HC, the following three main activities were conducted on a regular basis in every HC: first, the educational session that aimed to improve the knowledge on diabetes management of patients with diabetes, considering: diagnosis, symptoms, risk factors, medication, lifestyle, foot care, early and late complications, and dental care. It was conducted on average of twice a month by the UNRWA's trained health staff in UNRWA HCs. Second was the cooking sessions which were held once a month. These sessions were with the partnership of community kitchens at UNRWA's women program centers or vocational schools. It aimed to advocate for healthy cooking practices of the traditional Palestinian recipes. The participants and the medical staff, along with the local partners, have cooked and tasted different Palestinian recipes in a healthier way. The third sessions were focused on exercise and physical activity, and they were conducted in the local NGOs, UNRWA schools and HCs on average of twice a month. UNRWA's sports teachers and local physical trainers have volunteered in conducting the sessions.

\section{Data collection}

Demographics (age, gender, DM category (DMI, DMII or DMII\&HTN) and status control), body measurements (height, weight, and WC), blood tests (2-hour postprandial glucose tests (2hrPPGT), total cholesterol), blood pressure (BP) and their attendance for every session were collected first at baseline and then on monthly basis for 6 months. Each participant had a specific code, and all data were collected on a standardized Excel sheet, then consolidated from field offices to the headquarter. Also, questionnaires on knowledge and practice of diabetes care were administrated before and after the campaign (6 months). online supplementary questionnaire is available.

\section{Data handling and statistical analysis}

Data were entered in Excel and then transferred into SPSS V.21.0 for the statistical analysis. Descriptive analysis was done for participant demographics, disease pattern and the knowledge/behavior before and after the campaign. The pre/postcampaign data of weight, WC, body mass index (BMI), weight-to-height ratio (WHtR), PPGT, cholesterol and BP were assessed using the paired t-test. The analysis was performed for the complete sample, as well as for different patient categories; these categories were classified according to WHO guidelines for both BMI and WC. ${ }^{11-13}$ For example, baseline WC 


\section{AGE CATEGORY}

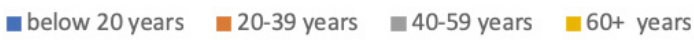

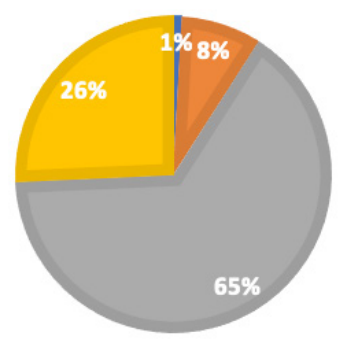

Figure 1 Age category.

for male was: normal $<94 \mathrm{~cm}$, risk $(94-102) \mathrm{cm}$ and high risk $(\geq 102) \mathrm{cm}$ and for female was: normal $(<80) \mathrm{cm}$, risk $(80-88) \mathrm{cm}$ and high risk $(\geq 88) \mathrm{cm} .{ }^{13}$ Also, weight change was categorized as follows: weight reduction by $\geq 5 \%$ (or $3 \%-5 \%$, or $1 \%-3 \%$ ), weight increase by $\geq 5 \%$ (or $3 \%-5 \%$, or $1 \%-3 \%$ ) or no change by $+1 \%$ to $-1 \% .{ }^{5}{ }^{13}$ Baseline BMI was categorized as $<30$ (non-obese) or $\geq 30 \mathrm{~kg} / \mathrm{m}^{2}$ (obese). ${ }^{11-13}$ Baseline WHtR, ${ }^{14}$ as we took the highest category, for males was categorized as $>63$ or $\leq 63$, WHtR for females as $>58$ or $\leq 58$. Baseline PPGT was $\leq 180 \mathrm{mg} / \mathrm{dL}$ (normal) or $>180 \mathrm{mg} / \mathrm{dL}$ (abnormal). ${ }^{15}$ Total cholesterol baseline levels were classified as $<200 \mathrm{mg} / \mathrm{dL}$ (normal) or $\geq 200$ (abnormal) ${ }^{16}$ and BP was considered to be in the hypertensive range $\geq 140 \mathrm{~mm} \mathrm{Hg}$ for systolic and $\geq 90 \mathrm{~mm}$ $\mathrm{Hg}$ for diastolic. ${ }^{12}$

\section{RESULTS}

Patient demographics

Out of the 1600 initial sample number, 1598 have completed the campaign, the average age was $52.9 \pm 10.8$ years figure 1, and the percentage of females was $74.0 \%$. Of those 1598 who completed the campaign, there were only 26 who had some missing data.

\section{Disease pattern}

According to participants who were categorized as DM\&HTN status, 62 (4\%) of them had DMI, 576 (36.0\%) had DMII, and $960(60.0 \%)$ had both conditions of DMII\&HTN.

\section{Body measurements}

Body weight

After the 6-month campaign, the average weight loss was $-2.6 \mathrm{~kg}(95 \%$ CI 2.4 to 2.7) table 1. Of all 1573 patients who completed the campaign, 345 (22\%) lost $\geq 5 \%, 388$ (25\%) lost $3 \%-5 \%$, and $472(30 \%)$ lost $1 \%-3 \%$ of their weight. However, $223(14 \%)$ had no major change in their weight $(-1 \%$ to $+1 \%)$, and more than $114(9 \%)$ had an increase in their weight.figure 2

\section{Body mass index}

After the 6-month campaign, the total BMI was reduced by 0.78 (95\% CI 0.41 to 1.2 ), a reduction of 0.76 (CI:
0.22-1.3) for females and 0.8 (CL: 0.71-0.94) for males figure 3. A significant change was observed in the BMI category of those who were obese (BMI $\geq 30$ ) (reduced from $36.4 \pm 5.9$ to $35.6 \pm 11.4$ ), and those who were non-obese $(\mathrm{BMI}<30)$ (reduced from $26.7 \pm 2.7$ to $26.1 \pm 2.8$ ).

\section{Waist circumference}

From the 1574 participants with full WC data, it was shown that WC significantly reduced from $108.7 \pm 14.1$ to 104 \pm 13.3. table 2, describs the high-risk WC for both gender.

\section{Biomarkers before and after the campaign}

Of all participants who have completed the campaign, a total of 1574 had completed their PPGT, cholesterol and $\mathrm{BP}$ readings table 3 . A significant reduction $(\mathrm{p}<0.005)$ was detected for those who were above the normal cut-off of point PPGT $>180$, cholesterol $>200$ and BP (systolic/ diastolic) $\geq 140 / 90 \mathrm{~mm} \mathrm{Hg}$.

\section{Patients' behavior and knowledge before and after the campaign}

We have observed improvements in the knowledge and lifestyle practices among the 1598 patients. Such developments were seen in the participants' cooking practices. For example, the practice of adding oil during cooking was reduced, and more participants have stated that they are using a measuring spoon for adding oil, for minimizing the amount of oil used during cooking. The percentages of participants having late night dinner (after 20:00) have decreased from 831 (52\%) before the campaign to $165(10 \%)$ after the campaign. We have observed an increase in the number of participants having the small and frequent healthy meals (three meals and two snacks) instead of the large fatty meals from $4 \%$ (69 patients) to $18 \%$ (277 patients). Also, the number of participants walking for $30 \mathrm{~min} /$ three times a week has increased from $779(49 \%)$ to $1229(78 \%)$. We are noting that the above practices were highly advocated during the campaign sessions.

\section{Patients' attendance during the campaign}

The percentage of attendance was $75.0 \%$ for education, $62.7 \%$ for cooking, and $73.5 \%$ for exercise sessions. These percentages are considered reasonably high, especially given the poor camp settings, infrastructure, and facilities provided for the campaign activities.

\section{DISCUSSION}

Globally, there have been many efforts to promote healthy lifestyle changes for patients with diabetes, with investment in modifiable factors, including diet, physical activity, and weight. ${ }^{17}$ Many studies indicated that patients with diabetes do not manage their disease on their own, even after receiving education about diabetes care. However, receiving diabetes education group-based intervention results in improvements in clinical, lifestyle and psychosocial outcomes. ${ }^{18-20}$ Other studies have 
Table 1 Changes in body measurements from baseline to the end of the campaign

\begin{tabular}{|c|c|c|c|c|}
\hline & Before campaign & After campaign & Changes & \\
\hline Parameters & Mean \pm SD & Mean \pm SD & Mean $(95 \% \mathrm{Cl})$ & $P$ value \\
\hline Weight (kg) & $86.5 \pm 16.4$ & $83.9 \pm 15.8$ & 2.6 (2.4 to 2.7$)$ & $<0.001$ \\
\hline Waist circumference (cm) & $108.7 \pm 14.1$ & $104.7 \pm 13.3$ & $4(3.7$ to 4.1$)$ & $<0.001$ \\
\hline Body mass index $\left(\mathrm{kg} / \mathrm{m}^{2}\right)$ & $33.5 \pm 6.8$ & $32.6 \pm 10.6$ & $0.78(.41$ to 1.2$)$ & $<0.001$ \\
\hline Body mass index-male & $31.1 \pm 6.8$ & $30.3 \pm 6.8$ & $0.8(.71$ to 94$)$ & $<0.001$ \\
\hline Body mass index-female & $34.3 \pm 6.6$ & $33.5 \pm 11.4$ & 0.8 (.22 to 1.3$)$ & $<0.001$ \\
\hline Waist-to-height ratio (WHtR)-male & $63.4 \pm 12.4$ & $61.2 \pm 11.2$ & 2.2 (2.0 to 2.5$)$ & $<0.001$ \\
\hline Waist-to-height ratio (WHtR) - female & $69.1 \pm 9.1$ & $66.6 \pm 8.7$ & 2.5 (2.3 to 2.6$)$ & $<0.001$ \\
\hline
\end{tabular}

shown that group-based training on self-management strategies for people with DMII is similarly effective. ${ }^{21}$

We believe that the diabetes campaign 'Life is Sweeter with Less Sugar,' which UNRWA has conducted by using a variety of clinical and behavioral interventions, was an effective tool in improving the clinical outcomes of patients with diabetes.

Patients' adherence and attendance level were considerably high, given the fact that they live in impoverished refugee camp setting; as they struggle with poor health, exacerbated by substandard housing, inadequate supplies of healthy food, and poor infrastructure for outdoor activities. $^{22}$ Some explanationson the level of commitment that was observed could be due to the type and diversity of the campaign activities and the positive experience coming from the group support. This patient adherence is unique compared with similar interventions, where the adherence is usually suboptimal. ${ }^{23}$ We think that many positive outcomes were related to the social gathering during the education, exercise and cooking sessions. Such results were seen in studies with evidence-based trends for achieving weight loss and increased physical activity an application for diabetes prevention and treatment, which indicated that group classes and campaigns focusing on a variety of nutrition, behavior, and exercise topics were also offered to help sustain adherence and motivation. $^{24}$

However, sustaining such positive outcomes of these interventions is a challenge, especially with the shortage of funding that UNRWA usually faces. ${ }^{25}$ From that perspective, the UNRWA's health department has been

\section{Reduction of weight (\%)}

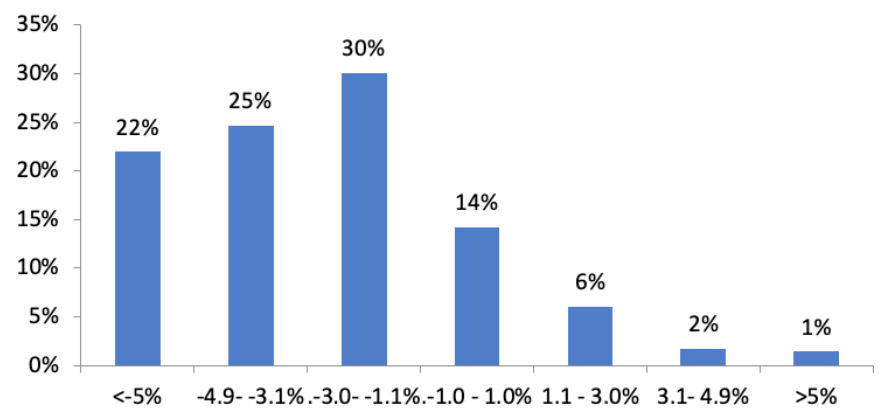

Figure 2 Percentage of weight change after the campaign. working on the NCD way forward for integrating such intervention within its primary healthcare program.

Weight loss with diet and exercise regimens has been shown to improve glycemic control effectively. Importantly, it has been demonstrated that in patients with DMII even a modest sustainable reduction of the initial body weight $(5 \%-10 \%)$ can reduce diabetes-related complications by improving glycemic control, lipid profiles and BP. ${ }^{26}$ From UNRWA's DM campaign weight loss results, it was found that $22 \%$ of patients have reduced $\geq 5 \%, 25 \%$ have lost $3 \%-5 \%$, and $30 \%$ have reduced $1 \%-3 \%$ of their weight, with an average of a $2.6 \mathrm{~kg}$ decrease in weight. However, this amount of weight loss is not enough for an obese patient with diabetes. ${ }^{51115}$ Moreover, maintaining weight reduction after completing the campaign can come with a struggle. To prevent weight regain after the campaign, UNRWA had put a sustainable follow-up plan for the participants after the campaign. ${ }^{27}$

$\mathrm{WC}$ is an independent risk factor for DMII. ${ }^{28}$ It is one of the best anthropometric predictors of abdominal fat. A WC higher than $102 \mathrm{~cm}$ for males and $\geq 88 \mathrm{~cm}$ for females is considered to be a risk factor for DM, cardiovascular diseases and other chronic diseases. ${ }^{28} 29$ Therefore, we chose to measure the changes in WC before and after the campaign, which had a significant decrease of $-4 \mathrm{~cm}$.

2hrPPG shows how tolerant the body is to glucose; therefore, it is a one-time level of blood glucose only. UNRWA used the 2 hrPPG results for diabetes monitoring and control during the campaign time. Back then, according to UNRWA's technical instructions, diabetes control is achieved when $2 \mathrm{hrPPG}$ becomes equal or less than $180 \mathrm{mg} / \mathrm{dL}(\leq 10.0 \mathrm{mmol} / \mathrm{L})$. Therefore, $2 \mathrm{hrPPG}$ was used as a blood glucose monitoring tool during the campaign. It has shown a significant reduction after the campaign. However, patients can impact results by not eating 2 hours before the test, heavy exercise, or having a meal or a snack right before the test. ${ }^{30}$ During UNRWA's clinical audit, it was shown that when using the HbAlc tests, patients with DM had lower results compared with that measured using 2 hrPPG (28\% vs $45 \%$ ). Thus, estimating diabetes control through $2 \mathrm{hrPPG}$ may be misleading as it overestimates control rates. ${ }^{7}$ Despite the financial constraints that UNRWA was and is facing, UNRWA has developed a stepwise implementation plan 


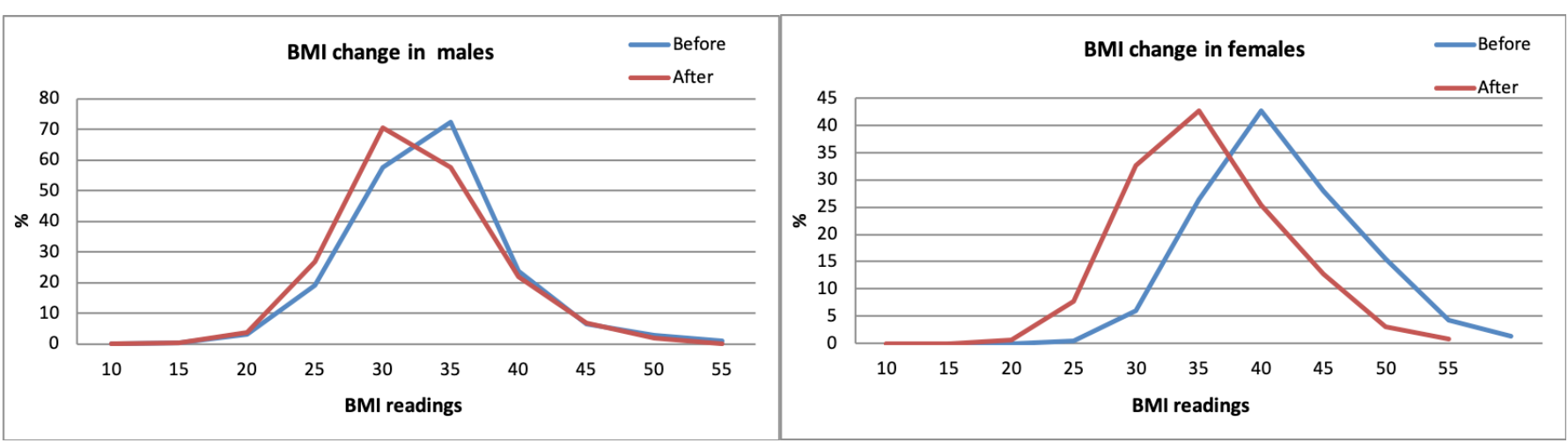

Figure 3 Percentage of change in all body mass index (BMI) categories before and after the campaign for both genders.

for the introduction of modern technologies (HbAlc) for patients who need and would benefit from it the most. ${ }^{2}($

Although there were missing data from a few sessions, the overall completion rate was high. We believe that the interactive campaign activities that were tailored to the refugee camp settings and patient's Palestinian heritage had an impact on the high participation rates. For instance, the cooking and exercise sessions were very tailored to the tradition and culture of the Palestinian refugees, especially the elder ones.

Resources are limited within a humanitarian agency such as UNRWA, so it is difficult to provide multiple weight management programs for a specific subpopulation of patients with various disease conditions, especially when such patients are scattered across a wide geographic radius. Yet, the results of such a campaign indicate that using an existing NCD care program embedded in UNRWA primary HCs is a feasible way to implement combined diabetes care management and weight loss. The adaptation of a variety of group sessions, such as cooking, education and exercise sessions, with local NGOs and community partnership has shown a positive impact on reducing weight, WC, $2 \mathrm{hrPPGT}$, cholesterol and BP.

\section{Limitations}

This campaign had more standardized methods and procedures compared with the first campaign conducted in 2013. However, there are some limitations to this campaign, which some were out of our control and others we will be addressing in future awareness campaigns:

1. There were missing data from a few sessions. However, the percentage of missing data is minimal, and we do not believe that these data will be significantly different from the rest of the cohort. Reasons reported for missing data from the health staff are: some patients could not attend a few sessions due to their family engagements, or they could not find suitable transportation from outside camps.

2. Similar to the first campaign, the number of females was higher than males, $74.2 \%$ female and $25.8 \%$ male. This might be because most males were at work during the time the sessions were conducted. Therefore, the future campaign should incorporate more male participation.

3. This study is quasiexperimental, therefore it is subject to validity issues due to lack of control group and randomization, but it is not feasible or ethical for a UN agency such as UNRWA to conduct a randomized controlled study on their beneficiaries.

\section{CONCLUSION AND RECOMMENDATIONS}

We have conducted a diabetes campaign for Palestine refugees with diabetes attending UNRWA HCs that focused on improving the level of awareness about diabetes care management and healthy lifestyle behaviors among Palestine refugees with DM, by using a variety of educational sessions. This campaign had a positive impact on body measurements and blood glucose in Palestine refugees with DM. Thus, use of existing NCD care resources in UNRWA HCs to deliver the principles of effective behavior change in the areas of weight loss, healthy eating, physical activity, DM status control and prevention of the disease deterioration could be more efficient in the areas of time, cost, and counseling.

In order to sustain the impact of this campaign, diabetes education and awareness about healthy lifestyle should be systematically integrated into the UNRWA NCD program. They could also help sustaining and empowering the local community involvement and NGO partnerships. Further follow-up studies (ie, cohort study

Table 2 High-risk waist circumference before and after the campaign in both genders

\begin{tabular}{|c|c|c|c|c|}
\hline & & Before & After & \\
\hline Waist circumference & Categories & Mean \pm SD & Mean \pm SD & $P$ value \\
\hline Waist circumference $(\mathrm{cm})-$ male & $\geq 102$ & $114.8+13.6$ & $110.2 \pm 12.5$ & $<0.001$ \\
\hline Waist circumference $(\mathrm{cm})$ - female & $\geq 88$ & $111+11.1$ & $106.9+10.9$ & $<0.001$ \\
\hline
\end{tabular}


Table 3 High-risk PPGT, cholesterol, and BP before and after the campaign

\begin{tabular}{lll}
\hline & Before campaign & After campaign \\
\cline { 2 - 3 } Biomarkers & Mean \pm SD & Mean \pm SD \\
\hline PPGT $>180$ & $258.6 \pm 69.1$ & $187.5 \pm 57.9$ \\
Cholesterol $>200$ & $234.6 \pm 37.2$ & $202.8 \pm 46.1$ \\
BP (systolic/diastolic) $\geq 140 / 90$ & $150.5+12.8 / 94.9+8.6$ & $132.8+12.4 / 83.4+11.8$ \\
\hline
\end{tabular}

BP, blood pressure; PPGT, postprandial glucose test.

or longitudinal) should be done to evaluate the long term effect of participants' DM status control and weight maintenance.

Acknowledgements Acknowledgement goes to all UNRWA health staff who participated in the DM campaign in the headquarter and across the four fields of operation (Jordan, Lebanon, West Bank and Gaza strip), also to the NGOs and local communities in the four fields.

Contributors NAK designed the study, collected and interpreted the data, carried out the data management, and wrote the article. YS designed the study, interpreted the data and revised the article. JM was responsible for critical editing of the text. YT interpreted the data and revised the article. WZ analyzed the data and produced the tables and figures. AS supervised the study and the data.

Funding This work was supported by the World Diabetes Foundation.

Competing interests None declared.

Patient consent for publication Obtained.

Provenance and peer review Not commissioned; externally peer reviewed.

Data availlability statement Data are available upon reasonable request.

Open access This is an open access article distributed in accordance with the Creative Commons Attribution Non Commercial (CC BY-NC 4.0) license, which permits others to distribute, remix, adapt, build upon this work non-commercially, and license their derivative works on different terms, provided the original work is properly cited, appropriate credit is given, any changes made indicated, and the use is non-commercial. See: http://creativecommons.org/licenses/by-nc/4.0/.

\section{REFERENCES}

1. United Nations Relief and Works Agency for Palestine Refugees in the Near East. What we do, 2015. Available: http://www.unrwa.org/ what-we-do

2. UNRWA. Annual report of health department, 2014. Available: http:// www.unrwa.org/resources/reports/health-department-annual-report2014

3. Husseini A, Abu-Rmeileh NME, Mikki N, et al. Cardiovascular diseases, diabetes mellitus, and cancer in the occupied Palestinian Territory. The Lancet 2009;373:1041-9.

4. Shahin Y, Kapur A, Seita A. Diabetes care in refugee camps: the experience of UNRWA. Diabetes Res Clin Pract 2015;108:1-6.

5. Kyrou I, Kumar S. Weight management in overweight and obese patients with type 2 diabetes mellitus. $\mathrm{Br} J$ Diabetes Vasc Dis 2010;10:274-83.

6. Gregg EW, Chen H, Wagenknecht LE, et al. Association of an intensive lifestyle intervention with remission of type 2 diabetes. JAMA 2012;308:2489-96.

7. Shahin Y, Kapur A, Khader A. Clinical audit on the provision of diabetes care in the primary care setting by United nations relief and works agency for Palestine refugees in the near East (UNRWA). $J$ Dm 2014;5.

8. abuKishk N, Van den Berg M, Seita A. Evaluation of the diabetes campaign for Palestine refugees with diabetes mellitus attending UNRWA health centers. Int J Food Sci Nutr Diet 2015;4:246-52.

9. Rad GS, Bakht LA, Feizi A, Mohebi S, et al. Importance of social support in diabetes care. J Educ Health Promot 2013;2:62.

10. Harris AD, McGregor JC, Perencevich EN, et al. The use and interpretation of quasi-experimental studies in medical informatics. $J$ Am Med Info Assoc 2006;13:16-23.
11. World Health Organization. Obesity: preventing and managing the global epidemic. World Health organization; 2000. (who technical report series 894), 2009. Available: http://apps.who.int/bookorders/ anglais/detart1.jsp?sesslan $=1 \&$ codlan $=1 \&$ codcol $=10 \&$ codcch $=894 \#$ 19

12. World Health Organization. Global reference list of 100 core health indicators, 2015.

13. Members EP, Jensen MD, Ryan DH, et al. Executive summary: guidelines (2013) for the management of overweight and obesity in adults: a report of the American College of Cardiology/American heart association Task force on practice guidelines and the obesity Society published by the obesity Society and American College of Cardiology/American heart association Task force on practice guidelines. based on a systematic review from the the obesity expert panel, 2013. Obesity 2014;22:S5-39.

14. Yoo EG. Waist-to-height ratio as a screening tool for obesity. Kor $J$ of Pedia 2016;59:425-31.

15. Juang PS, Henry RR. Treatment for Type 2 Diabetes. In: Feingold KR, Anawalt B, Boyce A, et al, eds. Endotext [Internet], 2013.

16. NHLBI N. High blood cholesterol: what you need to know. NIH Publication, 2005.

17. Forouhi NG, Misra A, Mohan V, et al. Dietary and nutritional approaches for prevention and management of type 2 diabetes. BMJ 2018;13.

18. Steinsbekk A, Rygg L, Lisulo M, et al. Group based diabetes selfmanagement education compared to routine treatment for people with type 2 diabetes mellitus. A systematic review with metaanalysis. BMC Health Serv Res 2012:12:213.

19. Greenwood DA, Kramer MK, Hankins Al, et al. Adapting the group lifestyle Balance ${ }^{\mathrm{TM}}$ program for weight management within a large health care system diabetes education program. Diabetes Educ 2014;40:299-307.

20. Rickheim PL, Weaver TW, Flader JL, et al. Assessment of group versus individual diabetes education: a randomized study. Diabetes Care 2002;25:269-74.

21. Deakin TA, McShane CE, Cade JE, et al. Group based training for self-management strategies in people with type 2 diabetes mellitus. Coch datab of syst reviews 2005

22. Sabatinelli G, Pace-Shanklin S, Riccardo F, et al. Facing socioeconomic decline: delivering health to Palestinian refugees. Babylon Nordisk tidsskrift for Midtstenstudier 2008.

23. Norris S, Nichols P, Caspersen C, et al. Increasing diabetes selfmanagement education in community settings $A$ systematic review. Am J Prev Med 2002;22:39-66.

24. Delahanty LM. Evidence-Based trends for achieving weight loss and increased physical activity: applications for diabetes prevention and treatment. Diabetes Spectrum 2002;15:183-9.

25. UNRWA. Cut of fund, 2018. Available: https://www.unrwa.org/ newsroom/official-statements/statement-unrwa-spokespersonsami-mshasha-implications-funding

26. American Diabetes Association. Obesity management for the treatment of type 2 diabetes. Sec. 6 . in standards of medical care in Diabetes-2016. Diabetes Care 2016;39(Suppl 1):S47-51.

27. Shahin YM, Kishk NA, Turki Y, et al. Evaluation of the Microclinic social network model for Palestine refugees with diabetes at UNRWA health centers. Journal of Diabetes Mellitus 2018;08:99-113.

28. Friedl KE. Waist circumference threshold values for type 2 diabetes risk. J of Dia Sci and Tech 2009:3:761-9.

29. Vazquez G, Duval S, Jacobs DR, et al. Comparison of body mass index, waist circumference, and waist/hip ratio in predicting incident diabetes: a meta-analysis. Epidemiol Rev 2007;29:115-28.

30. Gómez-Pérez FJ, Hemoglobin G. Fasting, two-hour Post-challenge and postprandial glycemia in the diagnosis and treatment of diabetes mellitus: are we giving them the right interpretation and use? Rev de Invest Clíni 2015;67:76-9. 